\title{
Limbos arqueológicos: una invitación al universo de los sitios extraoficiales en México
}

\author{
Víctor González-Robles* \\ Universidad Nacional Autónoma de México (México)
}

\begin{abstract}
Resumen: En México, existen 194 zonas arqueológicas abiertas al público por el Instituto Nacional de Antropología e Historia. No obstante, también hay muchos otros sitios que operan fuera del modelo de gestión federal y del marco jurídico vigente. Aquí se propondrá que ellos pueden denominarse limbos arqueológicos, siendo susceptibles de clasificarse según quién los administra y en qué régimen de propiedad de la tierra se encuentran. A través de la revisión de tres casos a lo largo y ancho del territorio nacional, se pretende ofrecer un primer acercamiento a sus problemas característicos y su dinámica común, considerando los aspectos jurídicos, burocráticos y socioeconómicos que fundan estos usos no autorizados del patrimonio arqueológico. Se concluye que ellos se encuentran en el limbo principalmente debido a las áreas grises en la legislación; vacíos que han sido aprovechados por los agentes sociales interesados y encausados hacia el aprovechamiento de las ruinas como recursos turísticos.
\end{abstract}

Palabras Clave: Arqueología; México; Patrimonio; Mercantilización; Turismo; Legislación; Antropología.

Archaeological limbos: an invitation to the universe of off-the-track sites (unofficial) in Mexico

Abstract: In Mexico, there are 194 archaeological zones open to the public under the custody of the National Institute for Anthropology and History. However, there are also many other sites that operate outside the federal management model and the current legal framework. These are called "limbos" here and are classified by who administers them and the land ownership regime. Through the review of three cases spread over Mexico, a first approximation of their key problems and shared dynamics is offered that factors in legal, bureaucratic and socioeconomic aspects that underlie the unauthorized use of archaeological heritage. It is concluded that they are "in limbo "mainly due to ambiguities in the legislation and loopholes that have been exploited by stakeholders to allow them to use of these ruins as a tourist attraction.

Keywords: Archaeology; Mexico; Heritage; Commodification; Tourism; Legislation; Anthropology.

\section{Introducción}

El objeto de este artículo son, concretamente, los sitios arqueológicos extraoficiales en México: es decir, espacios con vestigios prehispánicos que reciben visita pública sin tener propiamente las puertas abiertas por el Instituto Nacional de Antropología e Historia (INAH). Ante la falta de una nomenclatura y su situación residual respecto al marco legal vigente, se ha decidido llamarlos limbos arqueológicos. En esta bienvenida al tema, primero se explicará brevemente a qué se refiere el término según la tradición cristiana y, después, porqué estos espacios podrían ser denominados así.

Acto seguido, se ofrecerá una primera propuesta de clasificación según los regímenes de propiedad de la tierra y los agentes sociales que ejercen su custodia, denominándolos limbos arqueológicos privados, no federales y comunitarios. Luego, se presentarán los casos de estudio seleccionados (subrayando aspectos relativos a su disposición al público) para, finalmente, cerrar con la dinámica compartida en todos ellos, vinculada con rol actual de las autoridades municipales. En suma, la misión es brindar una imagen panorámica del usufructo por parte de terceras personas sobre el patrimonio prehispánico en el siglo XXI.

Universidad Nacional Autónoma de México (México); E-mail: vicgr77@gmail.com; https://orcid.org/0000-0001-7436-9909 
Este documento se propone como un primer vistazo a la tesis de maestría del autor, titulada Limbos arqueológicos: sitios extraoficiales en México. Para obtener los datos, se recurrió a la metodología propia de las etnografías de la arqueología (Castañeda y Matthews, 2008), realizando observación participante de las actividades realizadas en los espacios y entrevistas semiestructuradas grabadas a los principales agentes interesados en su gestión (desde arqueólogos hasta guías turísticos, funcionarios municipales, propietarios y ejidatarios). Además, se efectuó una investigación documental en archivos locales, hemerográficos e institucionales para, posteriormente, ordenar, codificar y procesar la información recabada con el software Atlas.ti.

\section{La historia del limbo}

En enero del 2007, el papa Benedicto XVI clausuró oficialmente las puertas del limbo: a través de un documento firmado con la Comisión Teológica Internacional pedía "dejar caer" la creencia en este espacio del otro mundo, calificándolo como una mera "hipótesis teológica" (Franceschini, 2017:14). Aunque el origen etimológico de la palabra es incierto (dado que carece de un equivalente en griego), ésta parece proceder del latín limbus y — desde tiempos de Virgilio— significa "orlo" o "borde" (a menudo, de prendas); pudiendo aplicarse también a situaciones de incertidumbre, inmovilidad o a fenómenos que carecen de contornos claramente definidos (Montanari, 1970; Franceschini, 2017:150).

Particularmente, en el discurso religioso el término limbus inferni apareció en la península itálica durante el siglo XII y fue teorizado por Santo Tomás de Aquino, de quién Dante Alighieri heredaría las ideas medulares para su propia visión poética en la Divina comedia (2016). En todos los casos, la palabra aludía al lugar y al estado después de la vida terrena al que iban las almas de quienes fallecieron con la única deuda del pecado original, esperando allí hasta ser salvadas por Cristo el día del juicio final. A grandes rasgos, se creía que dos personajes lo habitaban: por un lado, los "hebreos justos" del Antiguo Testamento (en el limbus patrum) y, por el otro, los infantes muertos sin haber recibido el sacramento del bautismo (en el limbus puerorum).

Particularmente, estos dos personajes constituían el "talón de Aquiles" del sistema teológico puesto que no encajaban dentro del esquema dual del paraíso celestial y el infierno. La situación no involucraba solamente a las autoridades eclesiásticas: era un drama cotidiano para la población medieval. Particularmente, el problema de los infantes muertos sin bautizar devino en prácticas "macroscópicas" por todo el viejo mundo, como la creencia de su "breve resurrección" para poder enterrarlos en el camposanto (Franceschini, 2017: 136).

No obstante, Dante reinterpretó las fuentes previas (esto es, a Santo Tomás, la literatura patrística y la tradición de los evangelios apócrifos) y creó una nueva versión del "círculo primero" de la vorágine infernal. Allí colocó, además, a los paganos virtuosos de la antigüedad en un "tenebroso mundo" iluminado por un solo "foco": un "noble castillo", rodeado por siete enormes muros y un "bello riachuelo" que — tras cruzar un mismo número de puertas - conducía a un "sitio abierto, luminoso y alto", de "verde esmalte" (Alighieri, Inf. IV. 106-120). La quietud era solo aparente: en sus palabras, sonaba "aquí un grave murmullo lastimero / - que advertí de suspiros, no de llanto- / del aura eterna hacía un hervidero / un duelo sin martirio, en su quebranto..." (Alighieri, Inf. IV. 25-28).

En consecuencia, el limbo dantesco se caracteriza por la ambivalencia y por un estado de suspensión: es un lugar de espera, tenebroso y luminoso, infernal y paradisiaco al mismo tiempo (Franceschini, 2017:1294-1306). El origen de la incertidumbre de sus habitantes era clasificatorio: allí la grandeza y la inocencia estaban condenadas al "dolor sin martirio" si carecían del reconocimiento institucional (en este caso, a través del bautismo, que borraba la etiqueta del pecado original). Empero, volviendo al uso original del concepto, este espacio nunca fue postulado como una verdad de fe definida por las autoridades vaticanas.

Esta breve reconstrucción de la génesis social del concepto revela que éste nació como una creencia fragmentaria y local del medievo, surgida "desde abajo" y no como una "región del miedo" impuesta desde lo alto del clero. Su función original residía en contener temores ampliamente difundidos, evocando las ideas paganas del otro mundo (Franceschini, 2017:265). No existió cosa tal como el limbo: históricamente han existido limbos, en plural. Dicho fuerte y claro, se trataría de una idea de "incierta naturaleza doctrinal" pero de amplia ascendencia social (Franceschini, 2017:162) que continúa vigente hasta la actualidad (en sus dos versiones, la cristiana y la dantesca). 


\section{Limbos arqueológicos}

De lo anterior, se concluye que puede llamarse limbo a cualquier espacio que se encuentre en una situación residual o que posea un lugar anómalo dentro de una institución, fungiendo como "sala de espera" (esto es, como un "destino intermedio y natural" entre dos opciones binarias; una definida como positiva y otra como negativa en ese mismo sistema de clasificación) (Franceschini, 2017:15). Concretamente, el sustantivo "limbo" con el adjetivo "arqueológico" se utilizará para referirse a cualquier sitio en la República Mexicana que reciba visitantes o tenga algún uso social sin estar abierto oficialmente al público.

Estos sitios suponen un fenómeno residual puesto que, en dicho país, los bienes muebles e inmuebles creados por culturas anteriores a la conquista española son considerados "propiedad inalienable, imprescriptible e inembargable de la nación” según la Ley Federal de Monumentos y Zonas Arqueológicos, Artísticos e Históricos de 1972 (LFMZAAH) (Cámara de Diputados, 2014). De esta manera, la única instancia autorizada para excavarlos, protegerlos y ponerlos a disposición de los visitantes es el Instituto Nacional de Antropología e Historia, órgano descentralizado de la administración federal fundado en febrero de 1939, por decreto de Lázaro Cárdenas (Sánchez Cordero, 2013; Olivé y Cottom, 2003; INAH, 2006, 2015, 2017).

Cabe aclarar que estas aseveraciones no figuran en la Carta Magna. Solamente, en el artículo 73 constitucional se menciona que el Congreso está facultado para legislar sobre estos bienes "cuya

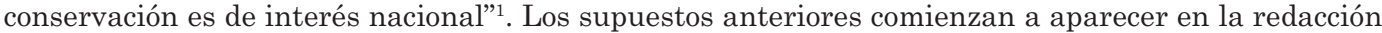
actual de la Ley General de Bienes Nacionales (LGBN), donde se establece que los monumentos arqueológicos "considerados como tal" son de "dominio público", "inalienables e imprescriptibles" (Cámara de Diputados, 2018: 3; Olivé y Cottom 2003:313-334). Esta articulación discursiva protege al patrimonio en el derecho, pero en los hechos vulnera el funcionamiento del INAH al dejar una suerte de espacio en blanco que, con una reforma, autorizaría a otras personas (como las entidades y municipios) para administrar estos bienes culturales.

Es importante señalar que la LGBN se reformó en el 2015 con la creación de la Secretaría de Cultura, poniéndola —en el artículo 30 - como entidad "competente para poseer, vigilar, administrar y conservar los inmuebles federales considerados como monumentos arqueológicos". Sin embargo, esta participación sigue contemplando la intervención directa del INAH y limita dichas "concesiones y permisos únicamente para la realización de actividades cívicas y culturales" (Cámara de Diputados, 2018:13).

Entonces, es debido a ese marco jurídico que el INAH funciona como un "monopolio administrativo" que concentra tanto el estudio científico del pasado antiguo como su gestión, produciendo un discurso y una práctica autorizada en materia de patrimonio arqueológico que opera hacia fuera a través de una "red" de "zonas" monumentales abiertas a la visita pública (Vázquez León, 2003; Ligorred, 2016). Empero, del total de 53,000 sitios registrados por la institución en el 2018, solamente los 194 "más relevantes" están habilitados para ello; es decir, ni siquiera el $1 \%{ }^{2}$. Esta riqueza patrimonial genera opiniones divergentes: para algunos, el órgano federal se enfrenta a una "misión imposible" (Nalda, 1993:131), mientras que — para otros_es más un problema metodológico de la disciplina arqueológica que una cuestión presupuestal (Gándara, 1997:78) ${ }^{3}$.

Sin embargo, este modelo de gestión encabezado por "el Leviatán arqueológico", en palabras de Luis Vázquez León, es visible de dos formas: por un lado, como zonas consagradas (por ejemplo, Teotihuacán, Chichén Itzá, El Tajín o Tulum, vinculadas con otros destinos turísticos) y, por el otro, como muchas otras que reciben pocos o ningún visitante (como Cuauhtochco o Chiapa de Corzo en 2018) (Puga, 2019). Esto habría provocado que, desde la década de 1990 se limitaran los trabajos de investigación e infraestructura a las zonas ya existentes, dado que las nuevas terminan por convertirse en una "exigencia adicional" en "recursos humanos, financieros y logísticos" invertidos en sitios "indeseados" que, como consecuencia no buscada, quedan vulnerables a la destrucción (Gómez, 2007; Vázquez León, 2003:171-174).

De cualquier manera, para que un sitio se transfigure en una "zona arqueológica" oficial debe pasar por un largo proceso burocrático, de investigación y negociaciones que suele tardar décadas. Esquematizando, en principio se necesita resolver la cuestión de la tenencia de la tierra, llegando a acuerdos con los propietarios y los diversos niveles gubernamentales (local, de la entidad y federal) ${ }^{4}$. Ideal pero no necesariamente, requeriría extensos proyectos arqueológicos para que — posteriormentesea autorizado el Expediente de Factibilidad para su apertura al público, por parte de la Dirección de Operación de Sitios (INAH, 2013). Hasta entonces podrá disponerse la infraestructura estipulada ${ }^{5}$ y dejar que los visitantes comiencen a llegar (INAH, 2006, 2015, 2017) ${ }^{6}$. Gracias a estos múltiples 
factores técnicos, legales e históricos, éstas no se distribuyen homogéneamente por las entidades federativas, de tal suerte que hay algunas como el Estado de México, Yucatán y Quintana Roo que poseen más de quince, otras como Sonora que cuentan con una y casos como el de Aguascalientes, que carecen de ellas.

Los limbos arqueológicos se insertan, pues, en este complejo entramado de contextos sociales, jurídicos, burocráticos e ideológicos, constituyendo espacios caracterizados por un usufructo del patrimonio prehispánico por parte de terceras personas (es decir, ajenas al INAH) y representando una manera de enfrentar la "espera" que implica el modelo de gestión federal-nacionalista antes descrito (Auyero, 2012). Asumiendo que "el Estado está materialmente imposibilitado para cuidar de todo el patrimonio arqueológico in situ" (Vázquez León, 2003:133), se propondrá que ellos existen por la forma de administración de los recursos del órgano responsable, las lagunas jurídicas en materia patrimonial y la poca vinculación que existe con las instancias judiciales (Gómez, 2007; Sánchez Cordero, 2013); problemáticas a la cuales se suman intereses políticos y económicos de actores locales que poseen el control del área.

En la mayoría de los casos, se trata de sitios que pasaron por proyectos aislados de investigación y/o restauración, pero que no recibieron el seguimiento antes descrito, o bien que tenían algún conflicto por la tenencia de la tierra. Dicho fácilmente, el proceso para su transformación de "sitio" a "zona arqueológica" quedó detenido y estos largos periodos de incertidumbre fueron aprovechados por los actores sociales que poseían el control fáctico del espacio. Eran originalmente "salas de espera" que terminaron por convertirse en un camino alterno al modelo del INAH.

Por otro lado, en América Latina las etnografías de la arqueología comenzaron en la década de 1990, precisamente con un estudio de caso sobre Chichén Itzá, en México (Castañeda, 1996). De ahí en adelante, los trabajos se han centrado en analizar el impacto del turismo en la práctica arqueológica, enfocándose casi exclusivamente en aquellos grandes sitios monumentales que fungieron — primero- como íconos del nacionalismo y, después, como destinos para visitantes internacionales: además de la recientemente nombrada "maravilla del mundo moderno" (Breglia 2006), destacan Teotihuacán (Delgado, 2012), El Tajín (Zúñiga, 2014; Salas-Landa, 2018; Holley-Kline, 2019) o Palenque (Vargas, 2018). Por motivos de extensión y de los objetivos del presente artículo no podrá ofrecerse aquí una revisión exhaustiva de la bibliografía previa.

Basta con advertir que los trabajos poseen el común denominador de mostrar al Estado mexicano como protagonista de los procesos de patrimonialización, que emanan directamente de su estructura y se imponen unilateralmente sobre las comunidades locales. De tal suerte, retratan cómo estos bienes arqueológicos han sido designados oficialmente como monumentos y, a partir de allí, su habilitación incorporaría a las poblaciones aledañas aunque solo temporal o marginalmente. Con esto, se quiere decir que durante el desmonte, restauración y colocación de infraestructura son ocupados como mano de obra y, una vez abierta, son "invisibilizados", desplazándolos incluso del paisaje como ocurrió en El Tajín (Salas-Landa, 2018). En el mejor de los casos, son contratados como custodios o bien, logran negociar el comercio ambulante dentro o fuera de las zonas, lo cual ha sido fuente de conflictos desde hace décadas en Teotihuacán o Chichén Itzá (Delgado 2012, Breglia 2006)

\section{Tipos de limbos arqueológicos}

No obstante, también es necesario enmarcar el universo de los limbos arqueológicos dentro de las transformaciones socioeconómicas de las últimas décadas. En este sentido, el auge de la industria turística de 1970 a la fecha, así como las políticas neoliberales de desregulación o abandono a los sectores productivos han llevado a los propietarios o poseedores de las tierras a revalorar el potencial cultural y pecuniario de los vestigios (Villalobos, 2014a; Oehmichen, 2013; Zúñiga, 2014). Ello los ha animado a abrir sus puertas y a conseguir intermediarios y socios para que dichos espacios, aún emergentes en el mercado de lo "alternativo", consigan una cantidad creciente de visitantes.

Así, contra los 53,000 sitios registrados y los 194 que forman parte de la "red" de zonas del INAH, esta investigación ha detectado hasta el momento la existencia de 110 limbos arqueológicos en 29 entidades federativas. La cantidad coincide con los registros de la Dirección de Operación de Sitios, que los contabiliza como 137 "sitios con grado de visita", si bien incluye en su listado algunos en los que la institución sí posee el control fáctico de los predios y/o que se encuentran en proceso de apertura 
(como La Pintada en Sonora, o Kulubá en Yucatán), según una solicitud de información interpuesta por el autor ante la Unidad de Transparencia de la dependencia (con el folio 16406 y con oficio del 10 de diciembre del 2019).

Por lo tanto, para ordenar el fenómeno se propondrá que el usufructo por parte de terceras personas de espacios prehispánicos opera bajo tres principales modalidades: 1) Limbos arqueológicos privados, conformados por personas físicas y/o morales que, en su propiedad, permiten el acceso al público y, en mayor o menor medida, a los especialistas para la conservación del lugar, así como a los guías de turistas para su promoción. 2) Limbos arqueológicos no federales (estatales o municipales), encabezados por instituciones legales que gestionan los vestigios, buscando crear cohesión social en el territorio (o bien, permitiendo concesiones mercantiles en su interior y utilizándolas con fines propagandísticos). 3) Limbos arqueológicos comunitarios, hechos "por, para y desde" grupos locales, en propiedad ejidal, usándolos como un recurso para el "ecoturismo" o como forma de autoproducción de su propia historia (Gnecco y Ayala, 2010:37; SECTUR, 2017).

El criterio clave de clasificación es, pues, el tipo de propiedad de la tierra (y, por ende, los agentes sociales que los administran), teniendo en mente el marco jurídico y los procesos de mercantilización de la cultura. En primer lugar, los limbos arqueológicos privados evocan, como su nombre lo indica, el incómodo tema de la posible privatización del patrimonio. Estos sitios existirían —en parte— dado que el único aspecto de los bienes arqueológicos que está fuera del mercado es la propiedad, no así el usufructo (Vázquez León, 2003:130), que es susceptible de concesionarse a terceras personas o funcionar a través de la política del dejar hacer y dejar pasar.

Sobre este punto, es necesario aclarar que la privatización explícita de las ruinas no puede ocurrir explícitamente debido al marco jurídico vigente antes esbozado, aunque de facto es un hecho de larga data que ha sido bien documentado en casos paradigmáticos como el de Chichén Itzá (Castañeda, 1996). Precisamente, en esto consiste la célebre "ambivalencia monumental" del patrimonio arqueológico en México: mientras las ruinas son consideradas propiedad de la nación, la tierra que las contiene puede seguir funcionando como propiedad privada (Breglia, 2006). Sobre estas paradojas legales se funda la operación de los sitios aquí denominados limbos, en cualquiera de sus variantes.

En segundo lugar, analizar los limbos arqueológicos no federales (estatales o municipales) es importante considerando que, desde hace pocos años, la Ley General de Asentamientos Humanos, Ordenamiento Territorial y Desarrollo Urbano (LGAH) establece que dichas autoridades pueden "coordinar y concertar acciones e inversiones entre los sectores público, social y privado" para la protección del patrimonio (Cámara de Diputados, 2016:46). Sin embargo, esta legalidad institucional no estaría exenta de riesgos: ante la corrupción, no es inusual que los proyectos sean utilizados con fines propagandísticos y comerciales para la administración en turno, o que sean abandonados si la siguiente no los considera compatibles con sus fines políticos.

Por último, analizar los limbos arqueológicos comunitarios es relevante si se toma en cuenta la reforma al artículo 27 constitucional que transformó los ejidos en propiedad privada en 1992 (Sánchez Nava. 1998:4; Breglia, 2006). En consecuencia, cabría preguntarse si —pese a que cada integrante ya es dueño de su parcela - la posible subsistencia de esta forma de organización colectiva del trabajo y cooperación mutua brindaría mayores facilidades para la ordenada habilitación de los espacios patrimoniales, que parecieran responder a la demanda global por productos turísticos "alternativos", "rurales" o "de naturaleza", en boga desde la década de 1990 (SECTUR, 2017:6).

\section{Limbos arqueológicos privados: La Proveedora, Sonora}

Para esta categoría, se seleccionó el sitio arqueológico de La Proveedora, localizado a ocho kilómetros de la ciudad sonorense de Caborca, a un costado de la carretera que conecta con Desemboque. El asentamiento se halla entre dos propiedades particulares dedicadas a la agricultura y la ganadería en pequeña escala. Allí se albergan más de 6,000 petrograbados (siendo — probablemente- uno de los sitios con mayor densidad en todo el continente) y si bien no hay una datación contundente, sus vestigios están fechados entre el periodo conocido como Agricultura Temprana (circa 1000 a.C.), incluyendo las características de la denominada Cultura Trincheras, cuya última fecha data para el 1450 d.C. (Villalobos, 2003). 


\section{Ilustración 1: Petrograbados en el sitio arqueológico de La Proveedora, Sonora, México.}

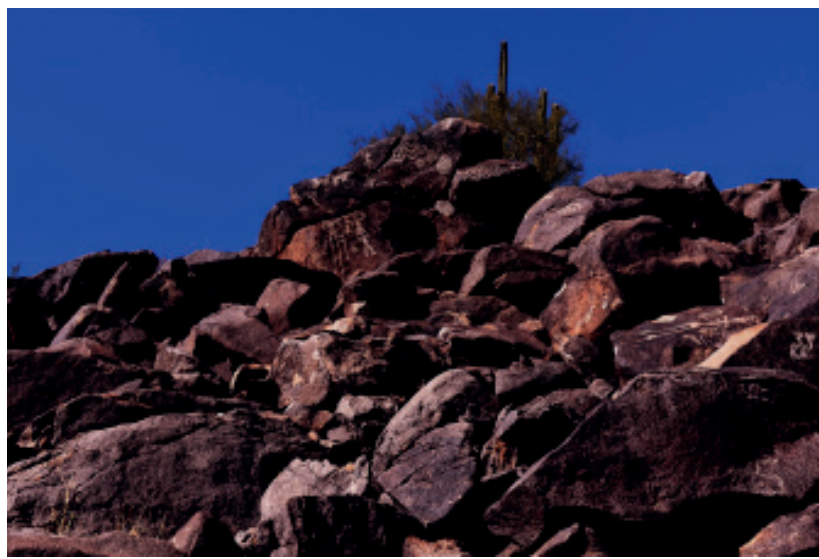

Fotografía del autor (2019).

Las investigaciones en el sitio comenzaron desde la segunda década del siglo pasado (Hinton, 1955) y se han profundizado a partir de los años 80 (Ballereau, 1988; Braniff, 1992; Villalobos, 2003), época en que empezaron a llegar los primeros turistas extranjeros (Jesús Meléndez, Caborca, 11 de enero del 2019). Desde entonces, el propietario del Rancho Puerto Blanco permite la entrada a los visitantes, cuyo costo hoy asciende a los 50 pesos, sin vigilancia ni mayor infraestructura que senderos de terracería y cercos de madera con candados para el ganado.

La promoción del sitio es coordinada entre el Ayuntamiento y la Oficina de Convenciones y Visitantes de Caborca, quienes certifican conjuntamente a los guías locales que llevan a los turistas al sitio. Gracias a esta estrategia, La Proveedora recibió en el 2018 a cinco mil visitantes, en su gran mayoría extranjeros o de la misma entidad, según el actual Coordinador de Turismo en el municipio (Ismael Nájera, Caborca, 17 de enero del 2019). Asimismo, el caso es relevante porque muestra que la percepción de los vestigios está fuertemente influida por la historia colonial de la región y por el imaginario nacionalista de lo prehispánico (Villalobos 2014b), considerando a "los petros" como una manifestación cultural de "gente que no sabía dibujar bien" (Carmen Gómez, Caborca, 17 de enero del 2019) o de "inditas a las que se les cayeron sus jarros" (Erika Rivera, Caborca, 10 de enero del 2019).

\section{Ilustración 2: Petrograbado con escena de cacería en La Proveedora, Sonora., México.}

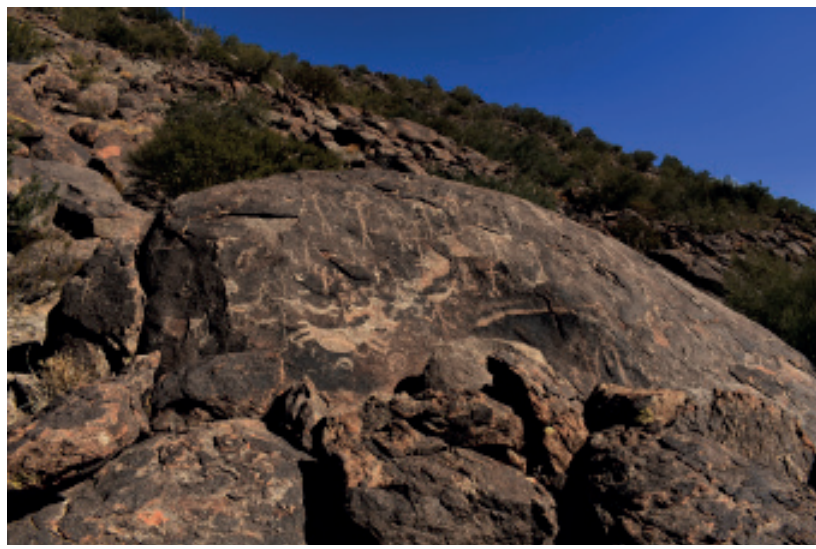

Fotografía del autor (2019). 
Por lo tanto, La Proveedora permitirá acercarse a las dinámicas propias de los limbos arqueológicos en un contexto no-mesoamericano: la central es, quizás, una forma de apropiación del patrimonio que nace por y para el turismo, reproduciéndose gracias a la intermediación con empresarios, guías locales y las autoridades municipales. A partir de este estudio de caso, podría anticiparse que la administración por parte de personas físicas, sin regulación alguna, se traduciría en problemas particulares como el vandalismo, el saqueo, la erosión por los visitantes, la falta de infraestructura y daños adicionales ocasionados por las otras vocaciones del terreno. A la par, el caso iluminará el desarrollo histórico de estos usos no autorizados de los vestigios, mostrando que no es un fenómeno nuevo sino que lleva ya varias décadas en curso.

\section{Ilustración 3: Mural monumental en La Proveedora, Sonora, México.}

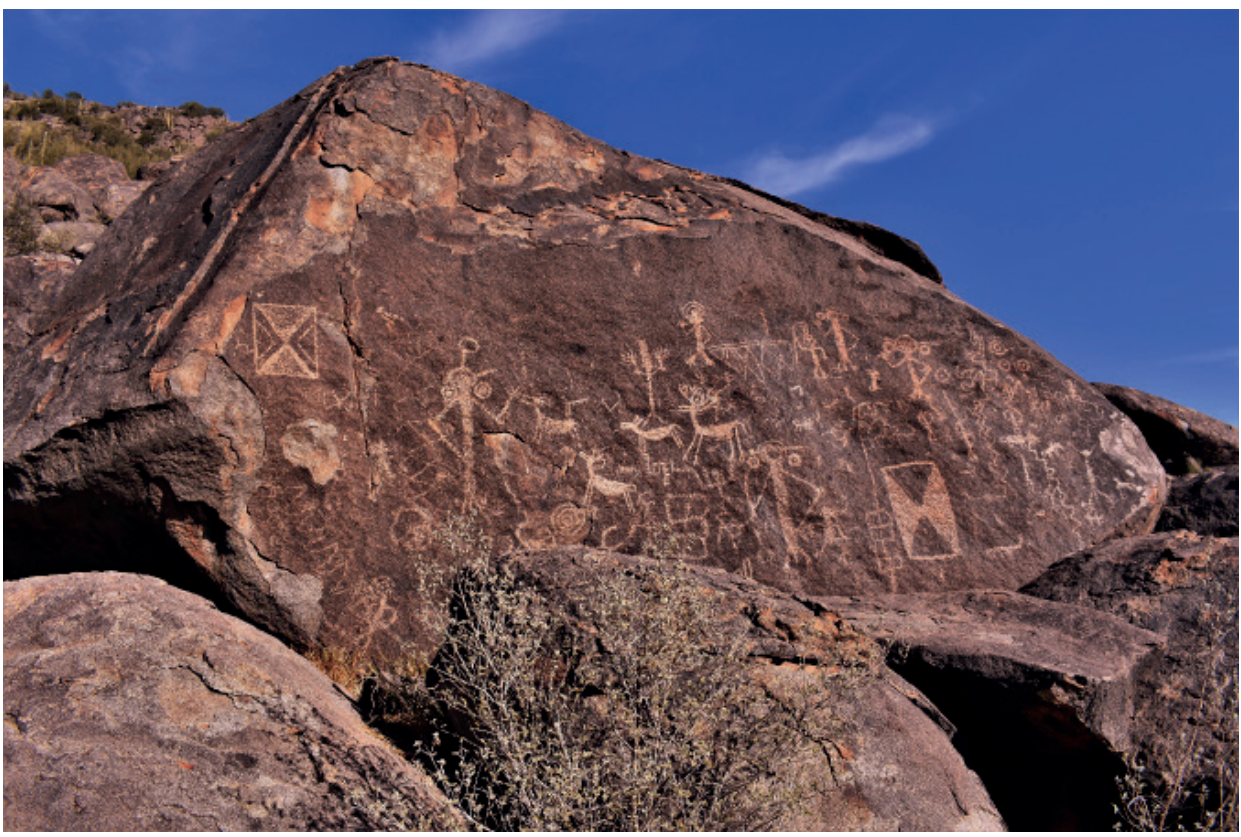

Fotografía del autor (2019).

Cabe señalar que, por razones de tiempo y recursos, la investigación no se acercará al usufructo por parte de personas morales, aunque es bien sabido que existen sitios arqueológicos dentro de exclusivos condominios en zonas turísticas como Huatulco y La Riviera Maya. Igualmente, se sugiere que la categoría podría tener otra variante: unos serían los limbos arqueológicos privados con voluntad de preservación y otros, los que carecen de esta misma intención de sus propietarios. Curiosamente, en Misantla, Veracruz, existen ambos casos: el primero sería el de Los Ídolos y el segundo, el de Paxil (Omar Ruíz Gordillo, Ciudad de México, 13 de agosto del 2018).

\section{Limbos arqueológicos no federales: Xoclán, Yucatán}

A cuatro kilómetros al poniente del Centro Histórico de Mérida, se encuentra Xoclán o "Los siete": un sitio arqueológico que se presume fue periférico a T'Hó7. En la actualidad, del periodo prehispánico, sobrevive un sacbé y un grupo de estructuras, coronado por un templo derruido de más de nueve metros de alto (Ligorred, 2013:273). Las excavaciones indicaron que su secuencia cerámica comenzó en el Preclásico Medio (300 a.C.-250 d.C.) y que su construcción fue paralela a la de T’Hó, durante el Clásico Temprano (entre el 250 y 300, hasta el 550 d.C.). Luego vivió un repunte hacia el Clásico Terminal, inducido a partir del hallazgo de elementos arquitectónicos de estilo Puuc (Abejez, 2012:637-639). 


\section{Ilustración 4: Basamento principal del sitio arqueológico de Xoclán, Yucatán, México.}

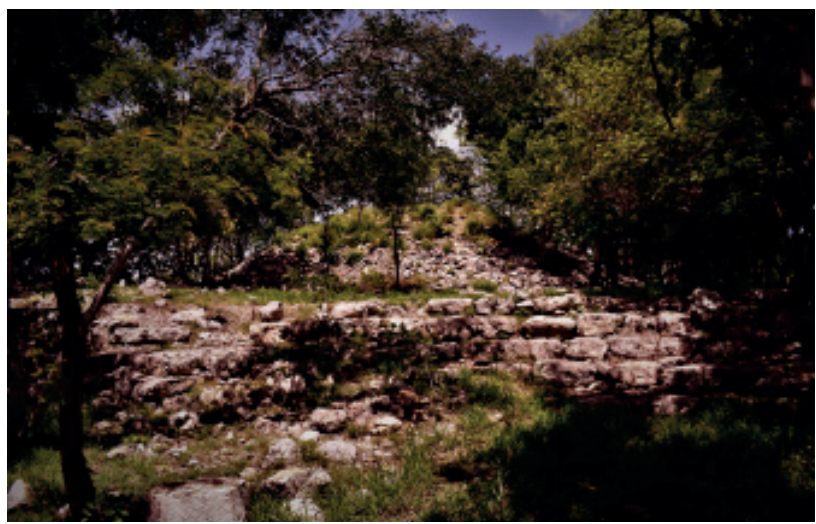

Fotografía del autor (2019).

El sitio se encuentra en propiedad municipal y es administrado por el Departamento de Patrimonio Arqueológico del Municipio de Mérida (DPA), ligado a la Dirección de Desarrollo Urbano y fundado en 1998, tras la declaración del Centro Histórico como Zona de Monumentos (Paredes Guerrero, Ligorred y Tresserras, 2006). Desde la década del 2000, se encuentra abierto como un parque público para las colonias aledañas, creadas en los años de 1980 para población obrera. En su interior, además de paseos cotidianos, se realizan eventos culturales de los vecinos y de asociaciones culturales mayas, tales como ceremonias religiosas o juegos tradicionales (Abejez, 2012:452). Hasta hace poco, Xoclán poseía una vasta infraestructura y servicios generales, comenzando por sanitarios, iluminación y estacionamientos, hasta ciclopista, miradores, palapas y juegos infantiles (Ligorred, 2013:274).

\section{Ilustración 5: El sacbé del sitio arqueológico de Xoclán, Yucatán, el único que ha logrado sobrevivir en contextos urbanos.}

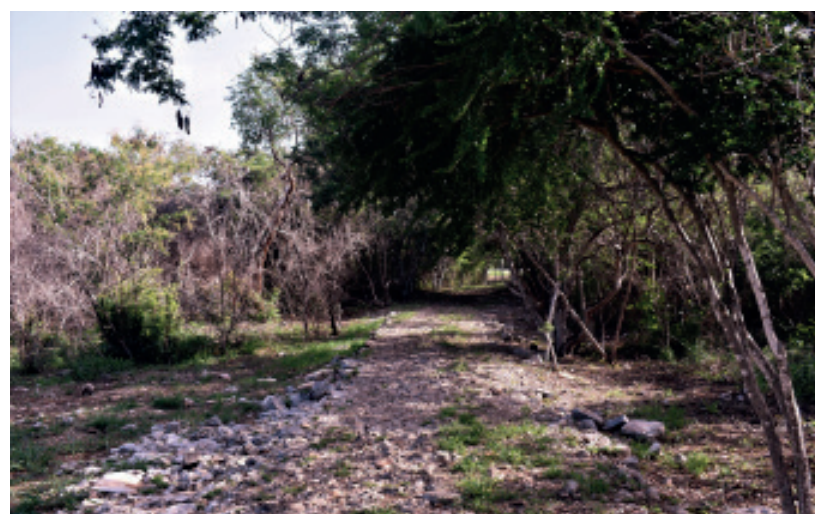

Fotografía del autor (2019).

Además, Xoclán ha sido objeto de negociaciones y conflictos — a veces abiertos — con el INAH, dinámica que podría ser característica de estos sitios debido a que las entidades y municipios usurparían una función exclusiva de la primera instancia (facultados por la LGAH). Esta suspicacia continúa a pesar de que ya existía un convenio firmado con el DPANM, pendiente de ratificar desde el 2007 (Ligorred, 2013:280; Abejez, 2012:438). Por lo tanto, podría decirse que la lógica principal que rige a estos limbos arqueológicos sería política, más que turística per se: expresaría una suerte de competencia con otras instituciones gubernamentales por el control de los recursos locales, a la par que buscan conformar identidad y captar votantes. 


\section{Ilustración 6: Mirador que da hacia la aguada del Parque Arqueo- -ecológico del Poniente, en Mérida, Yucatán, México.}

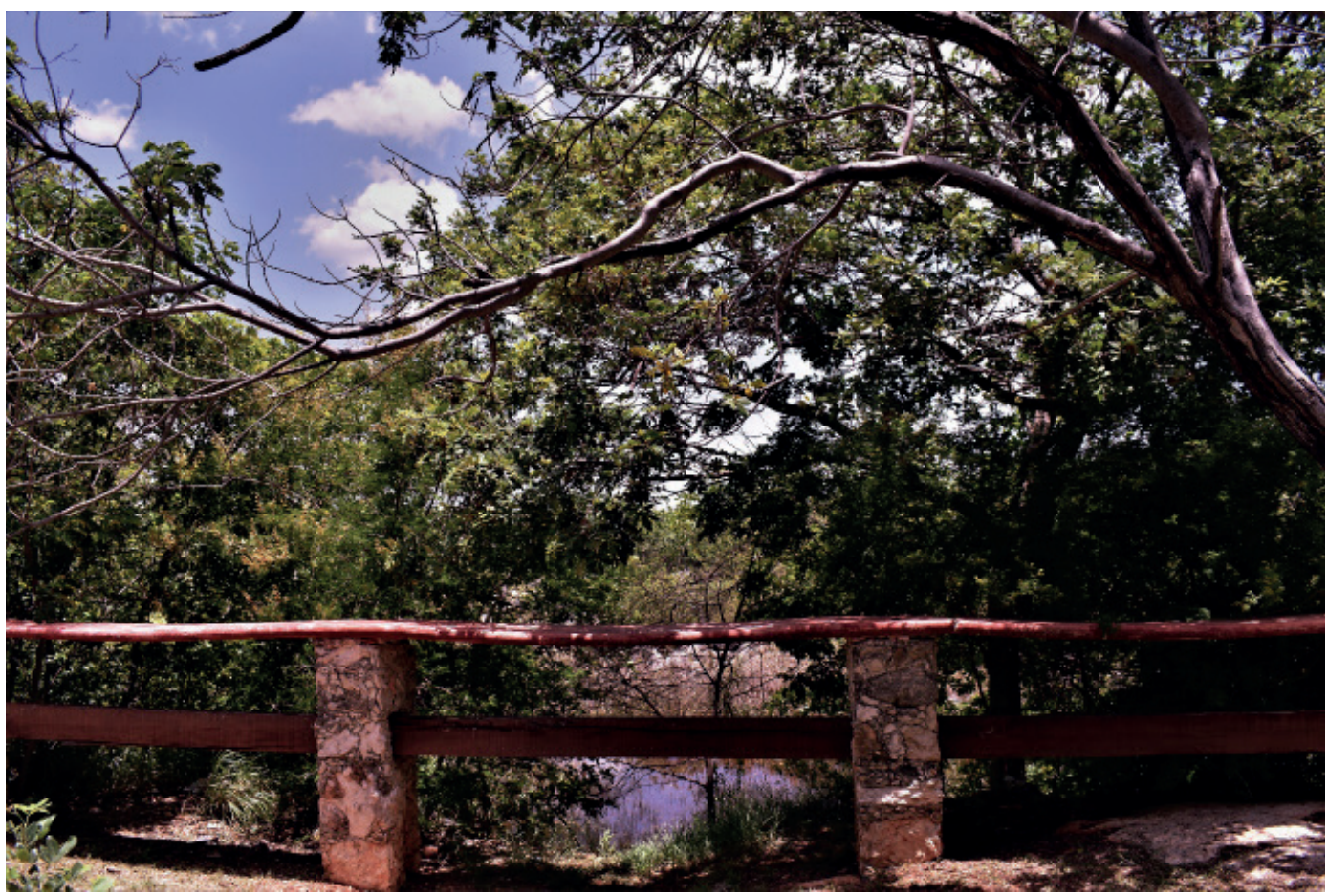

Fotografía del autor (2019).

Entonces, si bien Xoclán fue seleccionado por ser un caso favorable, también permitirá observar problemáticas propias de este tipo de espacios, aunadas a las vicisitudes de las administraciones gubernamentales: entre ellas, los posibles usos propagandísticos y el efecto coyuntural en los periodos en funciones, el desvío de recursos, la carencia de personal, la falta de mantenimiento, las concesiones a privados y la dificultad para realizar investigaciones. Asimismo, su actual carácter gratuito es relevante, obligando a reflexionar hasta qué punto la mercantilización turística es el motor exclusivo de estas formas de usufructo y cómo una reforma en la Constitución o en la LGBN podría cambiar el panorama en los años venideros, autorizando a estas personas públicas para gestionar - ahora sí oficialmente- el patrimonio arqueológico.

No obstante, la investigación dejará atrás el análisis de los limbos arqueológicos estatales ${ }^{8}$, así como el de sitios posiblemente gestionados por otras instituciones gubernamentales en sus predios. Hasta el momento, el autor desconoce si existe un caso explícito, aunque de facto las universidades públicas de las entidades federativas participan de manera cercana en la administración de ruinas en propiedades ajenas: es el caso de Oxpemul, por la Universidad Autónoma de Campeche o el de Mesa de Cacahuatenco, por la Universidad Veracruzana (Omar Ruiz Gordillo, Ciudad de México, 13 de agosto del 2018).

\section{Limbos arqueológicos comunitarios: El Boyé, Hidalgo}

El sitio arqueológico de El Boyé se localiza al interior de una comunidad homónima, ubicada a cinco minutos de la cabecera municipal de Huichapan, en el Valle del Mezquital hidalguense. Éste alberga 12 conjuntos de pinturas murales blancas, fechadas entre el Posclásico Tardío (1200-1521 d.C.) y el siglo XVIII, las cuales están dispuestas a lo largo de barrancas naturales sobre el arroyo del río Huisfhí (Peña, 2014). A la fecha, los trabajos se han limitado al registro y a la elaboración de propuestas de lectura que remiten al mito de la serpiente sagrada otomí, Bok’yä (Lorenzo, 1992; Peña, 2014).

Actualmente, las pinturas se encuentran en terrenos de un ejido mestizo fundado en 1936 (tras la partición de una Hacienda, con la Reforma Agraria) y, hasta hace unos años, era un espacio abando- 
nado. Sin embargo, impulsada por el Departamento de Turismo del Ayuntamiento de Huichapan, la población se organizó y comenzó a preparar el sitio para su visita pública, inaugurándolo en 2015. En un principio, limpiaron, cercaron, y colocaron caminos con elementos naturales que tenían a la mano a través de la "faena" comunitaria, modelo de trabajo con el que lo administran cuando no se encuentran desarrollando sus ocupaciones principales (básicamente, el cultivo o el empleo en el sector terciario de Huichapan). Gracias a recursos de instituciones gubernamentales como SEMARNAT y de programas como PACMyC (Programa de Apoyo a las Culturales Municipales y Comunitarias), los ejidatarios de El Boyé se encuentran en el proceso de construcción de infraestructura para brindar servicios turísticos, atendiendo a población local y de la región (entre Hidalgo y Querétaro). Hasta hoy, el sitio posee un estacionamiento, puentes naturales, senderos bien establecidos, cédulas informativas y su propio sistema de boletaje, pidiendo veinte pesos mexicanos como "donativo" para ingresar.

\section{Ilustración 7: Pintura mural conocida como "los danzantes" en el sitio arqueológico de El Boyé, Hidalgo, México.}

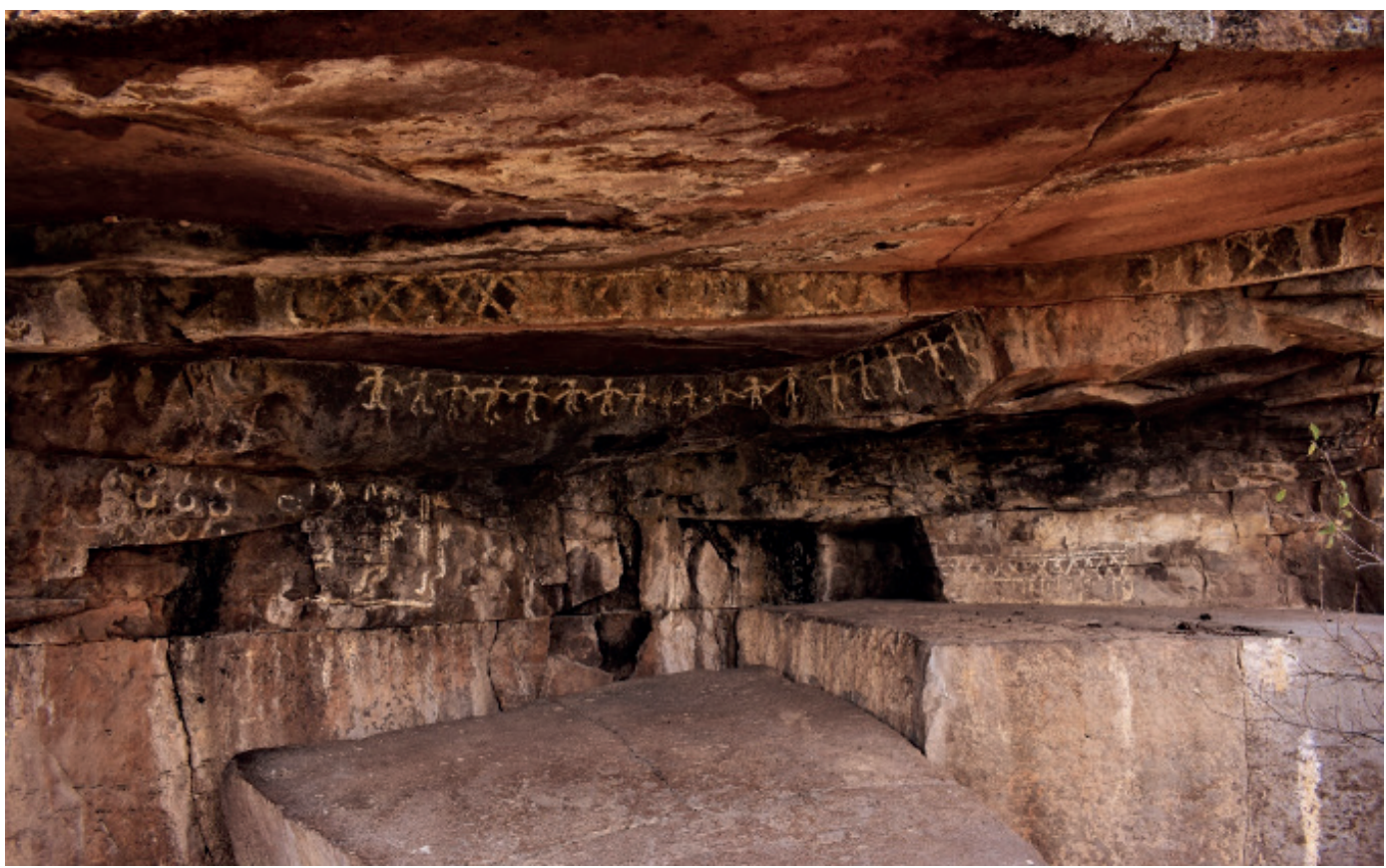

Fotografía del autor (2019).

No obstante, el estado de las representaciones plásticas es alarmante: muchas de ellas se están borrando por la erosión y algunas otras presentan repintados con cal (Peña, 2014). Este dato es ilustrativo de los problemas existentes en los limbos arqueológicos comunitarios (muchos de los cuales ya se vieron en los privados, aunados a los usos comerciales): a saber, la escasez de investigaciones y restauraciones profesionales, los efectos colaterales de la asesoría turística por parte de otras instituciones gubernamentales (entre ellos, la visita indiscriminada) y las posibles divisiones políticas al interior de las comunidades, factor que podría incluso revertir los procesos de patrimonialización si el producto turístico no obtiene el rendimiento económico esperado.

Asimismo, cabe aclarar que si bien su lógica principal sería turística, no obedecería a sus formas tradicionales sino a las modalidades alternativas del turismo "rural" o "de naturaleza", que ofertan el contacto con los grupos junto con sus recursos patrimoniales (SECTUR 2017). El Boyé ofrece la ventaja de presentar un modelo eficaz de organización que, en pocos años, ha movilizado el suficiente trabajo colectivo como para abrir el sitio prácticamente en las narices del INAH, quien se enteró de la habilitación un año después (Porfirio López, Huichapan, 16 de abril del 2019). 


\section{Ilustración 8: Pintura mural que representa una cacería de garzas en el sitio arqueológico de El Boyé, Hidalgo.}

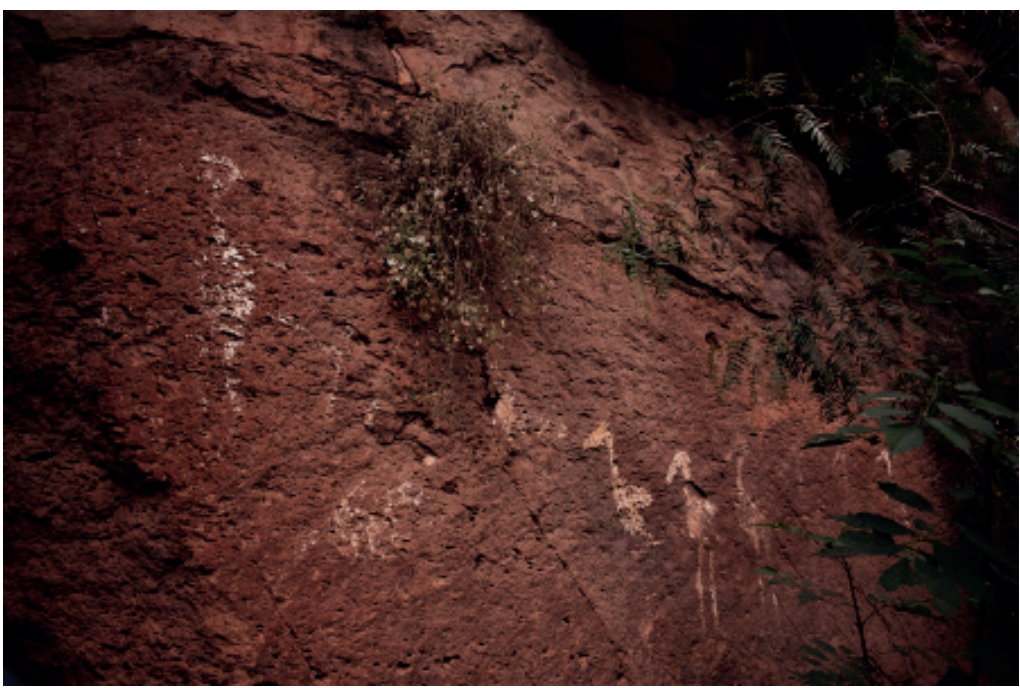

Fotografía del autor.

En este sentido, es importante señalar que no todos los limbos comunitarios poseen un carácter mercantil. Por ello, podría proponerse una subdivisión adicional: unos serían los ecoturísticos (como El Boyé o Yaxuná, en Yucatán) en los que el patrimonio es visto como un elemento identitario y como un recurso económico (Breglia, 2006; Rejón, 2007; Oehmichen, 2013), y otros los limbos rituales, de uso interno y donde la habilitación se realiza para conservar las tradiciones del mismo grupo social (a través de prácticas para propiciar los ciclos agrícolas), sin la intención expresa de llevar visitantes. Es el caso de algunos sitios en Yahualica, Hidalgo, o de Mesa de Cacahuatenco en Veracruz (Omar Ruiz Gordillo, Ciudad de México 13 de agosto del 2018).

\section{Ilustración 9: Pintura mural en el sitio arqueológico de El Boyé, Hidalgo, México.}

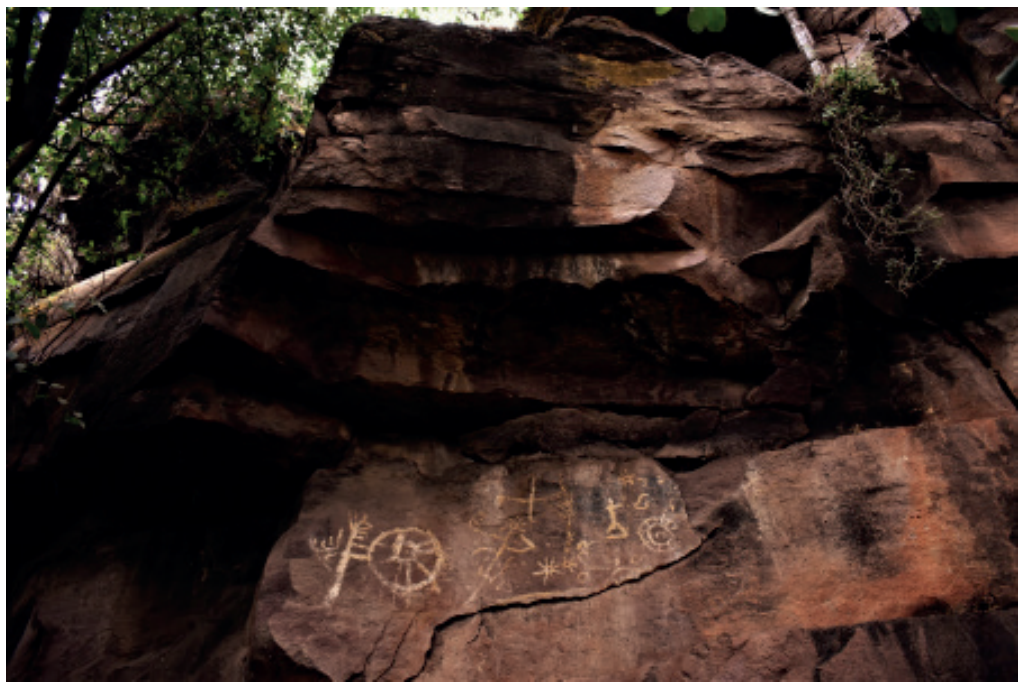

Fotografía del autor (2019). 


\section{Conclusión}

Hasta este punto, se ha argumentado que los sitios extraoficiales pueden ser llamados limbos arqueológicos debido a que son espacios que operan sin supervisión y fuera del sistema oficial (federal) de gestión del patrimonio arqueológico en México. Simultáneamente, representan un estado en el que terceras personas (físicas o morales, públicas o privadas) han logrado exitosamente el usufructo de aquellos bienes de dominio público. Bajo esta lógica, el concepto nacido en la tradición católica funciona como una metáfora que expresa el carácter residual (o extrajurídico) de estos discursos y prácticas encabezadas por agentes no autorizados.

Aquí se propuso una primera clasificación de estos espacios según las dos variables clave social y jurídicamente hablando (los agentes que los administran y el régimen de propiedad de tierra en que se hallan), en función de las cuales existirían —en principio- limbos arqueológicos privados, municipales y comunitarios. Luego, se mostró el caso elegido por cada escenario y algunos de sus problemas característicos, discutiendo sus dinámicas propias y posibles nuevas variantes en el modelo. A través de estos casos, se buscará construir una primera vista panorámica de estas formas de usufructo sobre el patrimonio prehispánico.

En suma, en los tres casos se aprecia la emergencia del turismo como potencial actividad económica a nivel municipal: de ahí que sean estas autoridades las principales mediadoras para la transformación de los sitios arqueológicos en espacios de consumo y/o recreación ciudadana. Esta intervención —solo directa en Xoclán - encontraría un sustento legal en normas de reciente creación (como la LGAH), así como en el vacío existente entre la Constitución Política y la LFMZAAH (Olivé y Cottom, 2003; Cámara de Diputados, 2014), en cuyos intersticios podría, próximamente, escribirse una reforma que autorizaría a terceras personas para gestionar el patrimonio prehispánico, sacando así a los sitios extraoficiales del limbo jurídico.

Finalmente, aquí se propuso utilizar el concepto del limbo para analizar una realidad que rebasa el marco legal y las capacidades institucionales para la gestión federal del patrimonio arqueológico en México, resaltando la ambigüedad e incertidumbre en que se encuentra debido a la multiplicidad de intereses proyectados sobre él. Los escenarios aquí mostrados ofrecen, sin duda, bastantes elementos para la sospecha, el debate y la crítica, aunque también es probable que abran un espectro de posibilidades en un futuro no tan lejano. La noción permite, además, acercarse al fenómeno sin emitir un veredicto: queda en manos del lector juzgar si se trata de infiernos o paraísos. La misión es contar las historias contemporáneas de estos enigmáticos espacios fronterizos, "donde el lamento suena como un suspiro" (Alighieri, Purg. VII. 29-30).

\section{Agradecimientos}

Este artículo es resultado de los seminarios "Teoría de la arqueología” y "Antropología, turismo y globalización", impartidos por Annick Daneels y Ana María Salazar en el Instituto de Investigaciones Antropológicas de la UNAM durante el 2019. Además, agradezco a todos en Caborca, Mérida y Huichapan por su confianza, cariño y colaboración.

\section{Bibliografia}

Abejez, L. 2012. El proyecto del parque ecoarqueológico de Xoclán, Mérida, Yucatán. Propuesta metodológica para la investigación de un sitio maya en un contexto urbano (tesis de doctorado), Universitat de Barcelona, publicación digital.

Alighieri, D. 2016. Divina comedia, Alianza, Madrid.

Auyero, J. 2012. Patients of the state: the politics of waiting in Argentina. Durhan: University Press. Castañeda, Q. 1996. In the museum of Maya culture: touring Chichén Itzá. Minesota: University Press.

Castañeda, Q. y C. Matthews. 2008. Ethnographic archaeologies: reflections on stakeholders and archaeological practices. Lanham: AltaMira Press.

Ballereau, D. 1988. El arte rupestre en Sonora: petroglifos en Caborca. Trace, 14 (12).

Braniff, B. 1992. La frontera protohistórica pima-ópata en Sonora, México. México: INAH. 
Breglia, L. 2006. Monumental ambivalence: the politics of heritage, Austin: University of Texas Press. Cámara de Diputados del H. Congreso de la Unión.

Breglia, L. 2012. Ley de Expropiación. Cámara de Diputados, México. Publicación electrónica, disponible en: www.diputados.gob.mx/LeyesBiblio/pdf/35.pdf, consultado el 11 de marzo del 2020.

Breglia, L. 2014. Ley Federal sobre Monumentos y Zonas Arqueológicos, Artísticos e Históricos. Publicación electrónica, disponible en: https://www.juridicas.unam.mx/legislacion/ordenamiento/ley-federal-sobre-monumentos-y-zonas-arqueologicos-artisticos-e-historicos, consultada el 22 de febrero del 2020.

Breglia, L. 2016. Ley General de Asentamientos Humanos, Ordenamiento Territorial y Desarrollo Urbano. Publicación electrónica, disponible en: http://www.diputados.gob.mx/LeyesBiblio/pdf/ LGAHOTDU_281116.pdf, consultado el 10 de marzo del 2019.

Breglia, L. 2018. Ley General de Bienes Nacionales. Publicación electrónica, disponible en: http://www. diputados.gob.mx/LeyesBiblio/pdf/267_190118.pdf, consultado el 10 de marzo del 2020.

Delgado, J. 2012. Movilidad comunitaria y patrimonio arqueológico en México (tesis de doctorado), Universidad Nacional Autónoma de México, publicación electrónica.

Franceschini, C. 2017. Storia del limbo, Milán: Feltrinelli.

Gándara, M. 1997. La arqueología oficial mexicana: causas y efectos, México: INAH.

Gnecco, C. y P. Ayala. 2010. “QQué hacer? Elementos para una discusión” en Pueblos indígenas y arqueología en América Latina, Fundación de Investigaciones Arqueológicas Nacionales, Banco de la República/CESO, Facultad de Ciencias Sociales, Universidad de los Andes, Bogotá: 23-48.

Gómez, F. 2007. "Análisis del desarrollo disciplinar de la arqueología mexicana y su relación con el patrimonio arqueológico en la actualidad”. Cuicuilco, 14(41):219-241.

Hinton, T. 1955. "A survey of the archaeological sites in the Altar Valley, Sonora". The Kiva, 21 (3-4).

Holley-Kline, S. 2019. Entangled archaeology, industry and labor in El Tajin, Mexico, 1880-2018 (tesis de doctorado), Universidad de Stanford, publicación electrónica.

INAH. 2006. Lineamientos para el manejo y operación de zonas arqueológicas con visita pública. Dirección de Operación de Sitios, México. Publicación electrónica. Documento de circulación interna.

INAH. 2013. Manual para la elaboración del Expediente de factibilidad para la apertura de zonas arqueológicas para la visita pública, Coordinación Nacional de Arqueología, Dirección de Operación de Sitios: México. Publicación electrónica, disponible en: https:/mexicana.cultura.gob.mx/en/repositorio/ detalle?id=_suri:MEDIATECAINFORME:TransObject:5bc501df7a8a0222efe68d3e, consultado el 10 de marzo del 2020.

INAH. 2015. Diagnóstico de las condiciones de operación de las zonas arqueológicas abiertas a la visita pública, Dirección de Operación de Sitios, Coordinación Nacional de Arqueología, México. Publicación electrónica. Documento de circulación interna.

INAH. 2017. Compendio de procedimientos relacionados con la operación de zonas arqueológicas abiertas al público, Dirección de Operación de Sitios, Coordinación Nacional de Arqueología, Subdirección de Protección Técnica, México. Publicación electrónica. Documento de circulación interna.

Ligorred, J. 1998. T'Hó, la Mérida ancestral, Dirección de Desarrollo Urbano, Ayuntamiento de Mérida, Mérida.

Ligorred, J. 2013. La gestión de los sitios arqueológicos en áreas urbanas del estado de Yucatán, México (tesis de doctorado), Universitat de Barcelona, publicación digital.

Ligorred, J. 2016. "La gestión del patrimonio arqueológico en los pueblos vivos" en Chávez, M. y L. Hernández (coords.). Diversidad, tradición e innovación en la gestión cultural (Chávez, M.; Hernández, L. coords.), Universidad de Guadalajara, Guadalajara, tomo 3: 33-50.

Lorenzo, C. 1992. Las pinturas rupestres del estado de Hidalgo, Consejo para la Cultura y las Artes de Hidalgo, Pachuca.

Montanari, F. 1970. Limbo. Enciclopedia dantesca, disponible en: http://www.treccani.it/enciclopedia/ limbo_\%28Enciclopedia-Dantesca\%29/, consultado el 30 de noviembre del 2019.

Nalda, E. 1993. "Elementos para la elaboración de una política de conservación del patrimonio arqueológico" en Florescano, E (ed.). El patrimonio cultural de México, FCE/CNCA, México: 129-144.

Oehmichen, C. 2013. Una mirada antropológica al fenómeno de turismo. en Oehmichen, C. (ed.). Enfoques antropológicos sobre el turismo contemporáneo, UNAM/IIA, México: 35-72.

Olivé, J. (coord.) y B. Cottom 2003. INAH: una historia, INAH, México, vol. III.

Paredes Gudiño, B. 2009. "Proceso de declaratorias de zonas de monumentos arqueológicos". en Mesa, S.; Castillo, M.; Sánchez Nava, P.; Medina, M. (eds). Memoria del registro arqueológico en México: treinta años, INAH, México: 611-657. 
Paredes Guerrero, B.; Ligorred, J. y J. Treserras, 2006. Plan estratégico del parque arqueo-ecológico de Xoclán: PEPAX, UADY, Mérida.

Peña, D. 2014. Negrura de lluvia entre dioses: el arte rupestre de El Boyé (tesis de licenciatura), Universidad Nacional Autónoma de México, publicación electrónica.

Rejón, L. 2007. "Conflicto social en el marco del desarrollo turístico de una comunidad maya de Yucatán. El caso Yaxuná”. Diario de campo, 95: 14-30.

Salas-Landa, M. 2018. "(In)visible ruins: the politics of monumental reconstruction in post-revolutionary Mexico", Hispanic American Historical Review, 98 (1): 43-76. Doi: 10.1215/00182168-4294456

Sánchez Cordero, J. 2013. "La defensa del patrimonio cultural. Su desafío". En Salas, H., Serra, M. e I. González (eds.). Identidad y patrimonio cultural en América Latina: la diversidad en el mundo globalizado, UNAM/IIA, México: 25-92.

Sánchez Nava, P. 1998. "El Procede y el patrimonio arqueológico". Revistas de Estudios Agrarios, 10 (1998): 1-16.

SECTUR. 2017. Estrategia para el impulso y desarrollo del turismo de naturaleza en México, Subdirección de Planeación y Política Turística, México. Publicación electrónica, disponible en: https://www.gob. mx/cms/uploads/attachment/file/278215/ETNM_v3_oct17.pdf, consultado el 23 de marzo del 2020.

Vargas, A. 2018. "The tourism and local development in World Heritage context. The case of Mayan site of Palenque, Mexico", International Journal of Heritage Studies, 2018, publicación electronica. https://doi.org/10.1080/13527258.2018.1428670

Vázquez León, L. 2003. El leviatán arqueológico: antropología de una tradición científica en México, CIESAS/ Miguel Ángel Porrúa, México.

Villalobos, C. 2003. Proyecto arqueológico de manifestaciones rupestres en La Proveedora, Sonora. Informe final. Temporada de campo marzo-abril 2003. Publicación electrónica. Documento proporcionado por el autor.

Villalobos, C. 2014a. "Arqueología mexicana en guías de turistas: educación y pasatiempo". Anales de Antropología, 48 (2): 41-73. http://dx.doi.org/10.1016/S0185-1225(14)70243-7

Villalobos, C. 2014b. “'Por qué en Sonora no hay arqueología? Nacionalismo y turismo en billetes de banco y folletos de viaje”. Región y Sociedad, 26 (59): 215-253.

Zúñiga, F. 2014. "Nuevos usos del patrimonio arqueológico de El Tajín, a través de los procesos de turistificación, mercantilización y espectacularización”. Anales de Antropología, 48 (2): 151-182. http://dx.doi.org/10.1016/S0185-1225(14)70247-4

Hemerografía y referencias digitales

INAH 2019. El tren maya, realidades y mitos. Mesa de análisis 1. Recuperado de: https://www.youtube. com/watch?v=Qe9EQQv7f_I, consultado el 6 de abril del 2019.

Puga, T. 2019. "Sitios arqueológicos de México, sin ni siquiera un visitante", El Universal, 31 de marzo del 2019, disponible en: https://www.eluniversal.com.mx/cartera/sitios-arqueologicos-de-mexico-sin-ni-siquiera-un-visitante, consultado el 10 de marzo del 2020.

Vázquez, V. 2019. "INAH, los retos de vivir ocho décadas", Diario de Querétaro, 10 de marzo del 2019, disponible en: https://www.diariodequeretaro.com.mx/local/barroco/inah-los-retos-de-vivir-ocho-decadas-3164943.html consultado el 10 de marzo del 2020.

\section{Notas}

1 En la fracción XXV, se añade que el Congreso tiene facultades para dictar leyes para "distribuir el ejercicio de la función educativa y las aportaciones económicas correspondientes a ese servicio público" entre la Federación, los estados y municipios (Olivé y Cottom, 2003:313).

2 Datos proporcionados públicamente por el actual Coordinador Nacional de Arqueología, Pedro Sánchez Nava el 25 de marzo del 2019 en un evento sobre el tren maya, disponible en YouTube. La cita también es suya (INAH, 2019).

3 Independientemente de las opiniones, el tema de los recursos federales de las instituciones culturales del Estado es crucial para la gestión del patrimonio. Para ilustrar la magnitud del problema bastan algunas cifras: según Diego Prieto, actual Director General del INAH, el organismo opera con un "déficit de recursos" de 900 millones de pesos relacionados con el personal eventual o contratado por honorarios. Ello pese a que en el 2018 generó ingresos que ascienden a los 710 millones de pesos por concepto de entradas a los recintos que administra. En el 2019, funcionó con un presupuesto de 3 mil 700 millones de pesos, de los cuales casi el 57\% fueron destinados al pago de nóminas (Vázquez, 2019).

4 Estas negociaciones se basan en lo establecido por la Ley de Expropiación, que establece al INDAABIN (Instituto de Administración y Avalúo de Bienes Nacionales) como autoridad responsable y pagando —en teoría— un precio equivalente a su valor comercial (Cámara de Diputados, 2012:4).

5 Esta infraestructura incluye desde vialidades para acceder o sanitarios, hasta una bodega de materiales, señalización y personal suficiente para prestar servicios y custodiar los vestigios todo el año (INAH, 2006, 2017). 
6 Aunque en el discurso todos los monumentos prehispánicos están protegidos por la LFMZAAH, en la práctica los sitios necesitan de un "instrumento" para su adecuada salvaguarda: el equivalente al bautismo sería una Declaratoria del Poder Ejecutivo publicada en el Diario Oficial de la Federación. Este acto jurídico le da al sitio un nombre y coordenadas específicas con delimitaciones de usos de suelo (Paredes Gudiño, 2009).

7 Mérida se construyó sobre la ciudad maya de T’Hó, que — según las fuentes documentales— fue un asentamiento “de primer rango" (Ligorred, 2013:262). Empero, con el paso de los siglos, el proceso de urbanización fue destruyendo paulatinamente sus vestigios prehispánicos, hasta que - a mediados del pasado- se demolieron las últimas construcciones visibles en el Centro Histórico para nivelar las calles. Hoy es un recuerdo contenido en monumentos y placas conmemorativas (Ligorred, 1998).

8 El caso inicialmente planteado fue Tlalpizáhuac, en el valle de Chalco, gestionado por el Instituto Mexiquense de Cultura. Este limbo arqueológico estatal se ubica en una colonia tomada por Antorcha Campesina y es utilizado como espacio para sus mítines políticos, así como para eventos propagandísticos en fechas como el 21 de marzo, en un evento de luz y sonido que fue descrito por la titular de "Turismo Ixtapaluca" al autor como un "Teotihuacán de tercer mundo" (Jessica Jiménez, Ixtapaluca, 15 de febrero del 2019). No obstante, además del contexto de delincuencia en la localidad, fue descartado porque no podía garantizarse un acceso seguro a la información, debido a conflictos internos entre el grupo de poder que encabeza esta administración en el municipio y Antorcha Campesina. 